\title{
Cancer as we know it
}

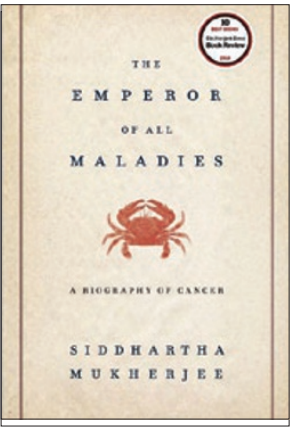

\section{The Emperor of All Maladies: A Biography of Cancer}

\section{Siddhartha Mukherjee}

Scribner, 2010

592 pp., hardcover, $\$ 30.00$

ISBN: 1439107955

\section{Reviewed by Victoria Aranda}

Cancer is the second leading cause of death in many industrialized countries, and almost one in three of us will have a direct encounter with it in our lives. Although the subject of cancer fills countless pages of scientific publications, gets incessant media coverage and occupies a prevalent place in science politics, few books have approached it in a comprehensive manner accessible to most readers. The Emperor of All Maladies by Siddhartha Mukherjee is, arguably, as good as it gets.

The prospect of digesting 4,000 years of medical history for a lay audience would make even the most committed cancer expert gasp. Mukherjee, a cancer clinician-scientist, sets out for this task with the right qualifications. He also proves to be an engaging storyteller. But his ability to empathize with his subjects, not only people with cancer but also doctors, scientists and advocates, is what ends up making this book an enthralling read for all audiences. Admittedly, the book can get quite complicated at times, particularly when Mukherjee delves into the complexity of cancer biology. But wading through these details is a rewarding endeavor: a clear picture emerges of where the fight against cancer currently stands, enabling readers to make an educated guess about the future.

The book covers the history of cancer from antiquity to the present. Reading it is akin to riding in a time machine: prepare to spend 500 pages hopping from Persian royal chambers to scientifically marginalized labs in dark basements to dreadful hospital wards, in almost-cinematic cuts and flashbacks. This daring approach succeeds in organizing the chronologically overlapping quests for a cure and a cause as they mesh with the mainstream of cancer science, medicine and policy.

The twists and turns of Mukherjee's story have a connecting thread throughout: the touching testimonies of people with cancer. Of them, Mukherjee writes recurring tales of "reckoning, fear, hope and resilience." Regardless of how much these stories resonate for each reader, they uniformly deliver the powerful message that the disease itself has not changed, and that every personal battle against it still encompasses the entire history of cancer.

Mukherjee captures the reader by choosing his main characters to symbolize the many minds and bodies that have carried the burden of this scourge. We can root for all cancer patients through Carla Reed,

Victoria Aranda is an associate editor at Nature Medicine. as she pushes through her treatments under Mukherjee's care. We can almost pity the arrogance of the early radical cancer surgeons, such as William Halsted, as they try to carve away tumors that are beyond their surgical reach, disfiguring patients along the way. We fall for the deceitful simplification that propelled Mary Lasker's unfaltering activism and Sidney Farber's audacious research to find a magic bullet and blast away the core of a coreless disease.

Although the book traces a comprehensive picture of cancer's history, it is anchored strongly around the iterative advances of empirical drug discovery, steered in the second half of the 20th century by the US National Cancer Institute. We follow doctors and advocates who, unfazed by the bodies piling up on the battlefield, use their partial victories to convince society into sanctioning an all-out 'war on cancer'.

Mukherjee disarms this premature attack with merciless logic. His hindsight illuminates the inevitability of our ensuing failure. Rallied by technological progress and impatient lobbying, science policymakers charted the timeline and defined the terms of our victory against cancer. It may be obvious to anyone professionally involved in cancer today that this thrust was doomed by our limited understanding of the disease at the time, but it is still useful to present the reasons for our defeat to the public. Mukherjee's insights might help quiet a continuing public demand for a cure.

Mukherjee juxtaposes the struggles of cancer therapy with the steady progress of the search for the biological origin of cancer. He argues that the recent wealth of scientific knowledge has generated the tools that are tilting the death toll of cancer slowly but surely: prevention, early detection and targeted therapies.

The author uses poignant examples to endorse this multipronged attack on cancer, and a few lengthy digressions to illustrate the need to join our forces against it. The story wanders out of focus with the retelling of the tobacco industry's woes, and the detour into AIDS territory reads as a drawn-out narrative of the author's ambivalence toward cancer advocacy. While it has helped transform cancer drug discovery, misguided public pressure can at times derail our quest. $\mathrm{He}$ hints at the need to inform the public dispassionately and without bias, and we can support his attempt to do so in this book.

With the merging of cancer biology and therapy, the book winds down as the author realizes that he "must confront the death of his subject." His sketch of the future is a wavering picture but is one of adamant hope. Mukherjee finds the progress of cancer science encouraging, despite the dangers of simplification to which the field has succumbed in the past.

Mukherjee offers up the growing population of cancer survivors as a testimony that, although a war against cancer might not be ours to win, we can make substantial progress against the disease. With this realistic conclusion, the book outlines a truce aimed at reducing untimely cancer deaths but concedes that cancer might always remain a part of us, a harbinger of our finitude. The reality of his subjects' harrowing journeys notwithstanding, the author posits that the integration of biology and therapy provides a hopeful framework for our renewed efforts. Scientists and doctors can certainly agree that the more we know about cancer, the closer we will be to defeating it, and this book is a step toward bringing the public onboard in that direction. 